\title{
Epidemiology and patterns of care for invasive breast carcinoma at a community hospital in Southern India
} Sambasivaiah Kuraparthy*1, Kumaraswamy M Reddy², Lakshmi Amancharla Yadagiri ${ }^{4}$, Mutheeswaraiah Yutla ${ }^{3}$, Phanindra Bobbidi Venkata ${ }^{2}$, Sarma VS Kadainti ${ }^{6}$ and Ramasubba PV Reddy ${ }^{5}$

\author{
Address: ${ }^{1}$ Department of Medical oncology, Sri Venkateswara institute of Medical Sciences, Tirupati, India, ${ }^{2}$ Department of Pathology, Sri \\ Venkateswara institute of Medical Sciences, Tirupati, India, ${ }^{3}$ Department of General Surgery, Sri Venkateswara institute of Medical Sciences, \\ Tirupati, India, ${ }^{4}$ Department of Radiology, Sri Venkateswara institute of Medical Sciences, Tirupati, India, ${ }^{5}$ Department of General Surgery, S.V. \\ R.R. General hospital, Tirupati, India and ${ }^{6}$ Department of Statistics, S.V. University, Tirupati, India \\ Email: Sambasivaiah Kuraparthy* - shivatirupati@yahoo.com; Kumaraswamy M Reddy - kumaraswamy_reddy@rediffmail.com; \\ Lakshmi Amancharla Yadagiri - sa_vskumar@yahoo.com; Mutheeswaraiah Yutla - mutheshyutla@yahoo.com; \\ Phanindra Bobbidi Venkata - pathphani@yahoo.co.in; Sarma VS Kadainti - sarma_kvs@rediffmail.com; \\ Ramasubba PV Reddy - kssivaiah@rediffmail.com \\ * Corresponding author
}

Published: 23 May 2007

World Journal of Surgical Oncology 2007, 5:56 doi:10.1 186/1477-78/9-5-56
Received: 2 October 2006

Accepted: 23 May 2007

This article is available from: http://www.wjso.com/content/5/I/56

(c) 2007 Kuraparthy et al; licensee BioMed Central Ltd.

This is an Open Access article distributed under the terms of the Creative Commons Attribution License (http://creativecommons.org/licenses/by/2.0), which permits unrestricted use, distribution, and reproduction in any medium, provided the original work is properly cited.

\begin{abstract}
Background: Breast cancer incidence in India is on rise. We report epidemiological, clinical and survival patterns of breast cancer patients from community perspective.

Methods: All breast cancer patients treated at this hospital from July 2000 to July 2005 were included. All had cytological or histological confirmation of breast cancer. TNM guidelines for staging and Immunohistochemistry to assess the receptor status were used. Either lumpectomy with axillary lymph node dissection or Modified radical mastectomy (MRM) was done for operable breast cancer, followed by 6 cycles of adjuvant chemotherapy with FAC or CMF regimens to patients with $\mathrm{PT}>\mathrm{I} \mathrm{cm}$ or lymph node positive or estrogen receptor negative and radiotherapy to patients after breast conservation surgery, PT size $>5 \mathrm{~cm}, 4$ or more positive nodes and stage IIIB disease. Patients with positive Estrogen receptor or Progesterone receptor were advised Tamoxifene $20 \mathrm{mg}$ per day for 3 years. Descriptive analysis was performed. Independent $\mathrm{T}$ test and Chi-square test were used. Overall survival time was computed by Kaplan - Meier method.
\end{abstract}

Results: Of I 488 cancer patients, I 22 (8.2\%) had breast cancer. Of 122 patients, $96.7 \%$ had invasive breast carcinoma and $3.3 \%$ had sarcoma. $94 \%$ came from the rural and semi urban areas. Premenopausal women were $27 \%$. The median age was 50 years. Stage I-6.8\%, II-45.8\%, III-22\%, IV-6.8\%, Bilateral breast cancer $-2.5 \%$. The mean PT size was $3.9 \mathrm{~cm}$. ER and PR were positive in $31.6 \%$ and $28.1 \%$ respectively. MRM was done in $93.8 \%$, while $6.3 \%$ patients underwent breast conservation surgery. The mean of the lymph nodes dissected were 3. CMF and FAC regimens were used in $48.8 \%$ and $51.2 \%$ of patients respectively. FAC group were younger than the CMF group ( $43.6 \mathrm{yr}$ vs. $54 \mathrm{yrs}, \mathrm{P}=0.000)$. Toxicities were more in FAC than CMF group, alopecia (100\% vs. $26.2 \%$ ), grade2 or more emesis (31.8\% vs. $9.2 \%)$, grade2 or more fatigue $(40.9 \%$ vs. $19 \%)$, anemia (43.1\% vs. $16.6 \%)$. Median Survival for the cohort was 50.8 months. ER positive patients had better median survival $(P=0.05)$.

Conclusion: MRM was the most frequent surgical option. CMF and FAC showed equivalent survival. FAC chemotherapy was more toxic than CMF. ER positive tumors have superior survival. Overall 3 year survival was 70 percent 


\section{Background}

Breast cancer is the most common cancer in the women of developed countries. Survival in breast cancer patients has improved substantially over the years as a result of multimodal treatment, comprising of local treatment by surgery and radiotherapy; systemic treatment by chemotherapy and hormonal therapy. Present research is focused on further refinement of each of these treatments in an attempt to preserve the organ and reduce the immediate and delayed toxicities. Studies on early stage breast cancer (EBC) from the developed countries have reported 20 year survival rates [1].

In India, without a significant reduction in carcinoma cervix, women are exposed to the increased risk of breast cancer, as demonstrated by the project "Development of An Atlas of Cancer In India", this study showed that ageadjusted incident rates of breast cancer was more than that of cervical cancer in 11 population based cancer registries (PBCR), with sole exception of a rural PBCR at Barshi $[2,3]$.

Health care inequalities exist in India. As a result of inappropriate concentration of comprehensive cancer centers to metros, only a fraction of total breast cancer patients could access these services. It is therefore, not unusual to find suboptimal treatment of breast cancer in the rural and semi urban regions of India. Various studies on breast cancer published from India reflect the disease profile and treatment characteristics unique to the urban rich and the middle class patients. The breast cancer profile at community level is largely unrepresented. Breast cancer is the second most frequent at this hospital, situated and catering to the rural patients [4]. We report the epidemiology, clinical characteristics and treatment patterns from a rural perspective. 3 year survival is included.

\section{Methods}

All breast caner patients who were treated at this hospital from July 2000 to July 2005 were included. All had cytological and/or histological confirmation of breast cancer. Patients were staged as per TNM guidelines. Chest-X ray, Ultrasound of liver was done for all, while Bone scan was done for Stage IIIB patients. Hormone receptor status was assessed by Immunohistochemistry, a quick score of 5 and above was considered positive. Cardiac status was assessed by Electrocardiogram and Echocardiogram for patients in anthracyline group.

\section{Surgery}

Surgery, either lumpectomy with axillary dissection or Modified radical mastectomy was done upfront for operable breast cancer. Some patients, who had surgery at peripheral hospitals and private clinics, were also included after slide review and provided that they had completed adjuvant treatment and follow up at our hospital. Premenopausal women who do not attain menopause after chemotherapy were advised bilateral oopherectomy.

\section{Chemotherapy}

All patients with $\mathrm{pT}>1 \mathrm{~cm}$ or axillary lymph node positive or estrogen receptor negative were given adjuvant chemotherapy. Adjuvant chemotherapy protocols included FAC (5 FU $600 \mathrm{mg} / \mathrm{m} 2$, Doxorubicin $60 \mathrm{mg} / \mathrm{m} 2$ and cyclophosphamide $600 \mathrm{mg} / \mathrm{m} 2$ given as i.v. infusion once every 21 days) or CMF regimens (Cyclophosphamide 600 $\mathrm{mg} / \mathrm{m} 2$, Methotrexate $40 \mathrm{mg} / \mathrm{m} 2$ and 5 FU $600 \mathrm{mg} / \mathrm{m} 2$ given on day 1 and day 8 as i.v infusion repeated every 28 days). Maximum of 6 cycles of chemotherapy were given. $\mathrm{CMF}$ regimen was given to elderly patients, with clinical cachexia and economically underprivileged. Patients having locally advanced cancer were given neoadjuvant chemotherapy, which was followed by surgery. Patients with positive Estrogen receptor and/or Progesterone receptor were advised Tamoxifene $20 \mathrm{mg}$ per day for 3 years, after completion of chemotherapy.

\section{Radiotherapy}

Radiotherapy was given to all those who underwent breast conservation surgery. Additionally, patients having $\mathrm{pT}>5$ $\mathrm{cm}$, four or more positive axillary lymph nodes, close or positive surgical margins and all stage IIIB patients were given radiotherapy. Patients without data on pT size and axillary nodes were advised adjuvant radiotherapy. Radiotherapy was given after completion of chemotherapy. Palliative radiotherapy for painful skeletal lesions was also given in metastatic setting.

\section{Statistics}

Descriptive analysis was performed for baseline demographics, response rates and toxicities. Independent T test was used to compare two chemotherapy groups. Chisquare test was used to explore the association between the categorical variables. Survival time was calculated from the date of diagnosis to the last follow up known to be alive or death. Kaplan - Meier method and log - rank test was used to compute overall survival.

\section{Results}

Of 1488 cancer patients treated during this period, 122 $(8.2 \%)$ had breast cancer. Of 122 breast cancer patients $118(96.7 \%)$ patients had invasive breast carcinoma, while $4(3.3 \%)$ patients had sarcoma. Sarcoma patients were not included for analysis. Clinical features are provided in Table 1 . Only $14.4 \%$ of women had meaningful education of degree and above. 55\% of women came from the rural background, while $39 \%$ of them were from semi urban areas. Premenopausal women comprised $27 \%$ of the cohort. Family history of any solid tumor was reported 
in $17 \%$ of patients (table 2 ). Mean age at first delivery was 21 years. Mean reproductive period (Age at Menopause minus Age at Menarche) was 32 years. Mean weight of the whole cohort was $56.8 \mathrm{~kg}$, while the mean Body Mass Index (BMI) was 24.1.

Early breast cancer and as well as metastatic breast cancer was marginal at $6.8 \%$ each. Of 96 operated patients, only $14(14.6 \%)$ had data on pT size. The mean pT size was 3.9 $\mathrm{cm}$. Fifty-seven $(48.3 \%)$ had information on receptor status. ER was positive in $38.6 \%$ of patients and PR was positive in $33.3 \%$ patients. Only $15.8 \%$ of patients were both ER and PR positive.

Of 96 patients who had surgery, 55 (57.3\%) patients had surgery at tertiary care hospital, while $42.7 \%$ patients had surgery at peripheral hospitals and private clinics. Mastectomy was done in $93.8 \%$ patients, while $6.3 \%$ patients underwent breast conservation surgery (BCS). Seventyone $(73.9 \%)$ had information on axillary lymph nodal status, out of these $33(46.5 \%)$ patients had information on the number of nodes dissected. The mean of the lymph nodes dissected were 3 . Of 96 patients who underwent surgery, $86(89.6 \%)$ patients received chemotherapy. Of 86 patients who received chemotherapy, 11(12.8\%) were in neoadjuvant setting. CMF and FAC regimens were used in $48.8 \%$ and $51.2 \%$ of patients respectively. The charac- teristics of the two chemotherapy groups are listed in the table 3 . The mean of chemo cycles received was 4.9 and 5.3 in CMF and FAC groups respectively $(P=0.27)$. The distribution of estrogen receptor positive patients were not significant between two chemotherapy groups (chisquare $P=0.5$ ). Thirty-eight patients received hormonal therapy. Mean duration of Tamoxifene treatment was 13.5 months.

\section{Toxicity}

Toxicities (Table 4) were assessed in patients who received chemotherapy. FAC regime was particularly more toxic across all the events reported. Mucositis was seen in $4.8 \%$ and $13.6 \%$ of CMF and FAC group patients respectively ( $P$ $=0.15)$. Alopecia was seen in all FAC patients and in $26.2 \%$ of CMF group ( $\mathrm{P}=0.000)$. Grade 2 and more, emesis was seen in $9.2 \%$ of $\mathrm{CMF}$ and $31.8 \%$ of FAC patients $(P=0.05)$. Grade 3 and above, nausea was seen in $2.4 \%$ of $\mathrm{CMF}$ and $9.1 \%$ of FAC patients $(\mathrm{P}=0.12)$. Grade 2 and more fatigue was seen in $19 \%$ of CMF and $40.9 \%$ of FAC group patients (Chi-square $\mathrm{P}=0.02$ ). High risk neutropenic sepsis was seen in $2.4 \%$ of CMF patients and $6.8 \%$ of FAC patients $(\mathrm{P}=0.58)$. One patient $(2.3 \%)$ died due to neutropenic sepsis in FAC group and none in $\mathrm{CMF}$ group. Significant anemia requiring transfusion was seen in $43.1 \%$ patients of FAC group and $16.6 \%$ of $\mathrm{CMF}$ patients $(\mathrm{P}=0.007)$.

Table I: Clinical features (Figures in parenthesis show percentage)

\begin{tabular}{|c|c|}
\hline Age (Median) & $\begin{array}{l}50 \text { years } \\
(23-72)\end{array}$ \\
\hline \multicolumn{2}{|l|}{ Stage } \\
\hline $\mathrm{I}$ & $8(6.8)$ \\
\hline ॥ & $54(45.8)$ \\
\hline III & $26(22.0)$ \\
\hline Metastatic & $8(6.8)$ \\
\hline Bilateral Breast Ca & $3(2.5)$ \\
\hline \multicolumn{2}{|l|}{ Axillary Lymph node } \\
\hline Positive & $42(35.6)$ \\
\hline Negative & $29(24.6)$ \\
\hline Data missing & $47(39.8)$ \\
\hline \multicolumn{2}{|l|}{ Estrogen Receptor } \\
\hline Positive & $22(18.6)$ \\
\hline Negative & $35(29.7)$ \\
\hline Data missing & $61(51.7)$ \\
\hline \multicolumn{2}{|l|}{ Progestorone Receptor } \\
\hline Positive & $19(16.1)$ \\
\hline Negative & $37(31.4)$ \\
\hline Data missing & $62(52.5)$ \\
\hline \multicolumn{2}{|l|}{ Surgery } \\
\hline Breast conservation & $6(5.1)$ \\
\hline Mastectomy & $90(76.3)$ \\
\hline \multicolumn{2}{|l|}{ Chemotherapy } \\
\hline FAC & $44(51.2)$ \\
\hline CMF & $42(48.8)$ \\
\hline Radiotherapy & $50(42.4)$ \\
\hline
\end{tabular}


Table 2: Frequencies of risk factors for breast cancer

\begin{tabular}{cccc}
\hline Parameter & Yes (\%) & No (\%) & Missing Data (\%) \\
\hline menopause & $70(59)$ & $32(27)$ & $16(14)$ \\
Abortion & $29(25)$ & $71(60)$ & $18(15)$ \\
Oral contraceptive pill use & $4(3)$ & $112(95)$ & $2(2)$ \\
Breast fed & $78(66)$ & $2(2)$ & $38(32)$ \\
Family history of any cancer & $20(17)$ & $85(72)$ & $13(11)$ \\
Education(Degree and above) & $17(14)$ & $69(59)$ & $32(27)$ \\
Diabetes & $25(21)$ & $60(51)$ & $33(28)$ \\
mixed diet & $91(77)$ & $12(10)$ & $15(13)$ \\
\hline
\end{tabular}

Additionally 12 patients (10.2\%) had lymph edema of the upper limb on affected side.

Two patients had radiation pneumonitis, one recovered and another died. Three patients had wound infection.

\section{Response}

Of 118 patients, 33 (28\%) relapsed, 52 patients (44.1\%) were in remission, $9(7.6 \%)$ had progressive disease. Twenty-four patients (20.3\%) had no follow-up.

\section{Survival}

Median Survival for the whole cohort was 50.8 months (95\% CI 30.7, 70.8). The 3 year survival was 70 percent (Figure 1). ER positive patients did not reach the median survival (Figure 2), whereas for ER negative patients it was 39.4 months $(\mathrm{P}$ value $=0.05)$. Median survival in post menopausal women was 39.4 months and while it was 50.8 months in premenopausal women $(\mathrm{P}=0.84)$. Median survival for CMF chemotherapy group was 50.8 months and FAC group did not reach median survival ( $P$ $=0.50)$.

\section{Patterns of relapse}

Of 33 patients, who had relapsed, $48.4 \%$ had skeletal metastases, $27.2 \%$ had lung metastases, $12 \%$ had liver metastases and $9 \%$ had brain metastases. Chest wall recurrence was seen in $33.3 \%$ patients and $21.2 \%$ patients had lymph nodal relapse.

\section{Discussion}

In this study we found that MRM was the most common primary surgical option for breast cancer. The adjuvant chemotherapy protocols CMF and FAC regimes have shown equivalent survival rates. CMF was less toxic. ER positive patients had superior survival. The compliance of i.v. chemotherapy was good; however the duration of hormonal therapy was suboptimal. Half of the patients did not have data on receptor status and one third on axillary lymph nodal status. Most tumors were receptor negative. The 3 year overall survival was $70 \%$.

Breast conservation surgery (BCS) followed by radiotherapy was shown to be equivalent to MRM in survival $[5,6]$. Therefore, BCS has become the standard of care for early breast cancer in developed countries [7], although some regional differences in the use of this treatment have been reported [8]. By contrast, MRM was the preferred primary surgical treatment for operable breast cancer in India, including in major urban centers. A study from Delhi showed only $11.3 \%$ underwent BCS, while MRM was performed in $88.7 \%$ patients [9]. Even in affluent non-west-

Table 3: comparison of chemotherapy groups

\begin{tabular}{|c|c|c|c|c|c|c|c|}
\hline variable & group & $\mathrm{N}$ & Mean & Stan Dev & $\mathrm{t}$ & mean Difference & Pvalue \\
\hline \multirow[t]{2}{*}{ Age } & CMF & 42 & 54.0 & 9.42 & 4.99 & 10.4 & 0.000 \\
\hline & FAC & 44 & 43.6 & 9.97 & & & \\
\hline \multirow[t]{2}{*}{ Weight (kg) } & CMF & 40 & 54.0 & 11.11 & -2.42 & -5.4 & 0.018 \\
\hline & FAC & 42 & 59.4 & 8.91 & & & \\
\hline \multirow[t]{2}{*}{ Body mass index } & CMF & 40 & 23.1 & 4.36 & -1.75 & -1.6 & 0.083 \\
\hline & FAC & 42 & 24.6 & 3.75 & & & \\
\hline \multirow[t]{2}{*}{ Lymph nodes } & CMF & 14 & 3.0 & 1.25 & 0.28 & 0.2 & 0.784 \\
\hline & FAC & 14 & 2.8 & 1.81 & & & \\
\hline \multirow[t]{2}{*}{ Tumor size (clinical) } & CMF & 32 & 6.1 & 2.61 & 0.67 & 0.7 & 0.505 \\
\hline & FAC & 40 & 5.4 & 1.98 & & & \\
\hline \multirow[t]{2}{*}{ Hemoglobin } & CMF & 30 & 11.6 & 1.93 & 0.03 & 0.0 & 0.977 \\
\hline & FAC & 35 & 11.6 & 1.68 & & & \\
\hline \multirow[t]{2}{*}{ Albumin } & CMF & 18 & 4.0 & 0.31 & 1.09 & 0.1 & 0.283 \\
\hline & FAC & 22 & 3.8 & 0.50 & & & \\
\hline
\end{tabular}


Table 4: chemotherapy induced toxicities

\begin{tabular}{cc}
\hline Toxicity & Frequency (\%) \\
Alopecia & $44(51.2)$ \\
Skin/Nail discoloration & $44(51.2)$ \\
Emesis (Grade2 and more) & $18(20.9)$ \\
Mucositis(Grade3 and more) & $8(9.3)$ \\
Nausea (Grade3 and more) & $5(5.8)$ \\
High risk febrile neutropenia & $3(3.5)$ \\
\hline
\end{tabular}

ern countries this seems to be the case [10]. Access to radiotherapy facility was shown to influence the use of BCS [11]. In the present study, only $6.3 \%$ patients underwent breast conservation surgery. Generally, the axillary dissection for most patients was inadequate, as exemplified by the fewer number of nodes examined. Further more, the pathology reports were lacking on pT size and histological grade. These two are very crucial information for optimal treatment of breast cancer. The advanced stage and lack of radiotherapy facility are possible reasons for the infrequent use of BCS.

The EBCTG meta-analysis published in 1992 reported that the adjuvant chemotherapy reduced the annual odds of recurrence by $40 \%$ in patients younger than 50 years of age with ER negative tumors and by $33 \%$ in those with ER positive disease [12]. In patients above 50 years, adjuvant chemotherapy had reduced the annual odds of recurrence by $30 \%$ in ER negative tumors and by $18 \%$ in ER positive tumors. Overall, poly chemotherapy significantly reduced the annual odds of recurrence and death by $24 \%$ and $15 \%$ respectively. Anthracyline based regimens resulted in a survival benefit when compared to CMF-like regimens,

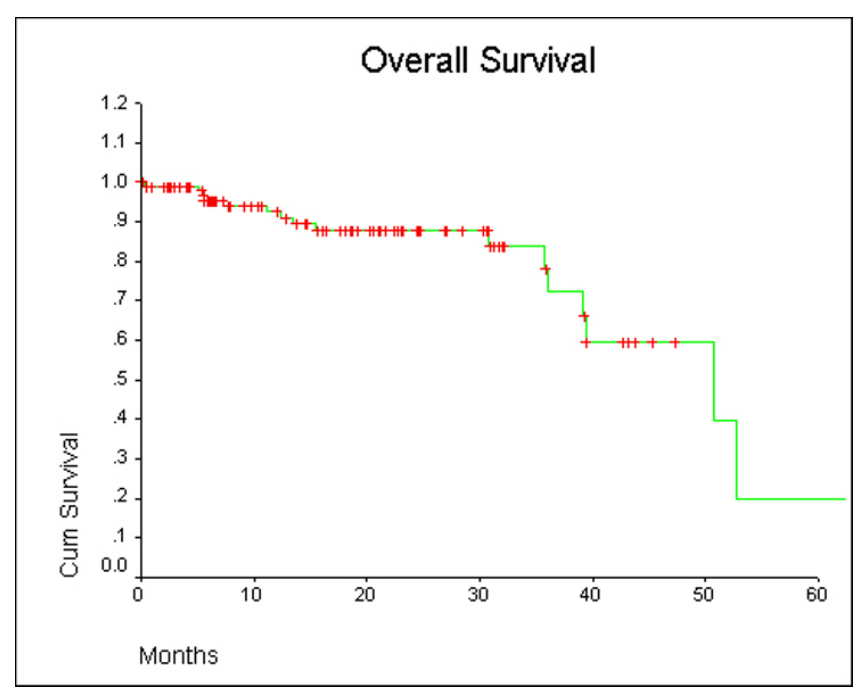

Figure I

Overall survival. with improvement in annual odds of recurrence and death of $11 \%$ and $12 \%$, respectively. Toxicity profile is different for $\mathrm{CMF}$ and anthracycline based regimens. Various toxicities were more with FAC than CMF in elderly [13]. FAC regimen is costlier than the CMF; the cost becomes even more, if the cost of supportive treatment for toxicities are taken in to consideration. For these reasons, we have preferred CMF for poor, elderly patients. The compliance with either chemo regimen was good. Expectedly the FAC regimen was more toxic and the median survival between the two groups was not statistically significant. To demonstrate $10 \%$ difference between the two groups would require a large sample size.

Estrogen receptor is a well established predictive and prognostic factor in breast cancer. The recent international consensus on treatment for early breast cancer [14], the panel affirmed that the first consideration was endocrine responsiveness and suggested categorization of breast cancer in to endocrine responsive, endocrine non responsive and tumors of uncertain endocrine responsiveness. Therefore, testing for estrogen and progesterone receptor status is critical to plan optimal treatment for breast cancer.

Estrogen receptor positive rates were reported to be lower in Indian patients than those in western countries. A study

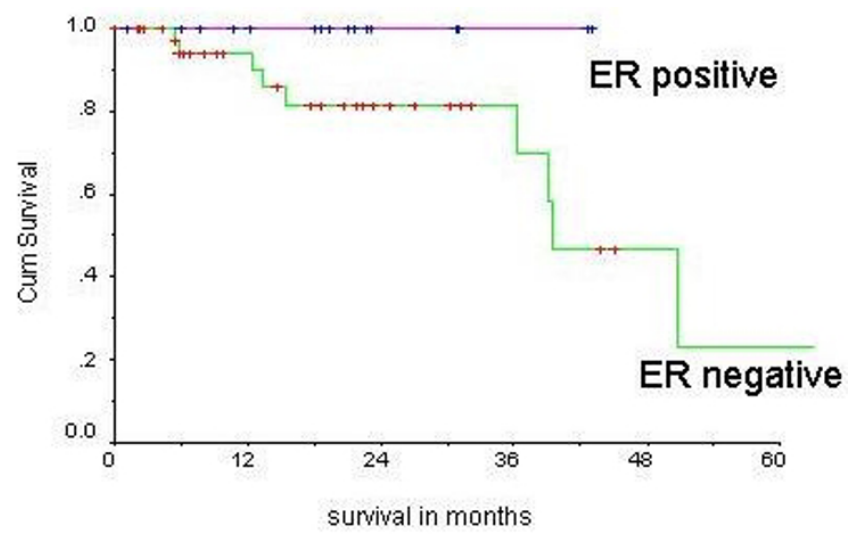

Figure 2

ER status and survival. 
from Mumbai, found ER and PR positive rates of 32.6\% and $46.1 \%$ respectively [15]. Additionally, not all patients in India undergo the hormone receptor testing, as shown by a study from Delhi; only 35.5\% patients had receptor testing [9]. In India, there is a concern about rising incidence of breast cancer in young women; premenopausal women comprised $50 \%$ of the cohort in an urban study [9]. However in the present study the premenopausal women formed one-fourth of the cohort. This suggests that the breast cancer in young Indian women may be an urban

phenomenon.

In our study, only $48.3 \%$ Patients had hormone receptor testing. The mean duration of compliance with tamoxifene was 1.3 years. Even in developed countries the use of Tamoxifene was found to be suboptimal at community level [16]. Nonetheless, the reasons for this poor compliance in our patients require investigation and improvement.

Survival rates in breast cancer patients have been reported from some registries in India. Five-year overall survival rate in the Bangalore population based registry was $42.3 \%$ [17]. The Madras Metropolitan Tumor Registry reported survival rates of $80 \%, 58 \%$ and $48 \%$ at 1 year, 3 year and 5 years respectively [18]. A study from Kerala showed five year survival rate of $40 \%$ [19]. In the present study, the overall survival rate at 3 years was $70 \%$, demonstrating the feasibility of achieving comparable results at community level by improving the infrastructure.

\section{Conclusion}

To move forward in the breast cancer care, breast cancer physicians in India face major challenges. Some of them are lack of information on histological grade of the tumor, pT size, axillary lymph node clearance and receptor status. The skills required by surgeons and pathologists to address these issues can be imparted by conducting workshops and Continuing Medical Education programs. On chemotherapy front, Taxanes and the monoclonal antibodies are unlikely to be used at community level in India, in the foreseeable future. The sequential adjuvant hormonal treatment, with falling prices of aromatase inhibitors, is promising. Therefore, it is necessary for the oncology community in a poor country like India to develop minimum practice guidelines for breast cancer management.

\section{Competing interests}

The author(s) declare that they have no competing interests.

\section{Authors' contributions}

SK: Designed the study, supervised the data collection, analysis and writing of the manuscript.
KRM: participated in designing the study and critically the paper

RRPV: contributed to the study design and write up

MY: contributed in writing up.

AYL: reviewed the manuscript critically

PBV: contributed in writing up

SKVS: Data analysis and critically reviewed the paper.

All authors read and approved final manuscript.

\section{Acknowledgements}

We acknowledge the assistance of Ms Chandi Priya. Y (Medical Records Department), Ms. G.R. Bhanu and M. Srinivasulu (Dept of Oncology) in data collection.

\section{References}

I. Veronesi U, Cascinelli N, Mariani L, Greco M, Saccozzi R, Luini A, Aguilar M, Marubini E: Twenty-year follow-up of a randomized study comparing breast-conserving surgery with radical mastectomy for early breast cancer. N Engl J Med 2002, 347: $1227-1232$

2. Development of cancer atlas of India - A project of National Cancer Registry Program (Indian Council of Medical Research), First All India Report 2002, I: I I-I8.

3. Yeole BB, Kurkure AP: An epidemiological assessment of increasing incidence and trends in breast cancer in Mumbai and other sites in India, during the last two decades. Asian Pac J Cancer Prev 2003, 4:5 I-56.

4. Sambasivaiah K, Kumaraswamy reddy $M$, Venkataramanappa $M$, Phanindra B, Lakshmi AY, Sarma KVS: Cancer Patterns in the Rayalaseema Region of Andhra Pradesh. Indian J Med Paediatric Oncol 2004, 25:9-15.

5. Morris AD, Morris RD, Wilson JF, White J, Steinberg S, Okunieff P, Arriagada R, Le MG, Blichert-Toft M, van Dongen JA: Breast-conserving therapy vs. mastectomy in early-stage breast cancer: a meta-analysis of 10-year survival. Cancer J Sci Am 1997, 3:6-I2.

6. Fisher B, Anderson S, Bryant J, Margolese RG, Deutsch M, Fisher ER, Jeong JH, Wolmark N: Twenty-year follow-up of a randomized trial comparing total mastectomy, lumpectomy, and lumpectomy plus irradiation for the treatment of invasive breast cancer. N Engl J Med 2002, 347:|233-I24I.

7. Wilson RE, Donegan WL, Mettlin C, Natarajan N, Smart CR, Murphy GP: The 1982 national survey of carcinoma of the breast in the United States by the American College of Surgeons. Surg Gynecol Obstet 1984, 159:309-318.

8. Farrow DC, Hunt WC, Samet JM: Geographic variation in the treatment of localized breast cancer. N Engl J Med 1992, 326: $1097-1101$.

9. Raina V, Bhutani M, Bedi R, Sharma A, Deo SV, Shukla NK, Mohanti BK, Rath GK: Clinical features and prognostic factors of early breast cancer at a major cancer center in North India. Indian J Cancer 2005, 42:40-45.

10. Akhtar SS, Nadrah HM: Assessment of the quality of breast cancer care: a single institutional study from Saudi Arabia. Int J Qual Health Care 2005, 17:301-305.

1I. Schroon AT, Brenin DR, Kelly MD, Knaus WA, Slingluff CL Jr: Impact of patient distance to radiation therapy on mastectomy use in early-stage breast cancer patients. J Clin Oncol 2005, 23:7074-7480.

12. Early Breast Cancer Trialists' Collaborative Group: Systemic treatment of early breast cancer by hormonal, cytotoxic, or immune therapy. 133 randomised trials involving 31,000 recurrences and $\mathbf{2 4 , 0 0 0}$ deaths among $\mathbf{7 5 , 0 0 0}$ women. Lancet 1992, 339:71-85. 
13. Hurria A, Brogan K, Panageas KS, Pearce C, Norton L, Jakubowski A, Zauderer M, Howard J, Hudis C: Patterns of toxicity in older patients with breast cancer receiving adjuvant chemotherapy. Breast Cancer Res Treat 2005, 92:15I-156.

14. Goldhirsch A, Glick JH, Gelber RD, Coates AS, Thurlimann B, Senn $\mathrm{HJ}$ : Panel members. Meeting highlights: international expert consensus on the primary therapy of early breast cancer 2005. Ann Oncol 2005, 16:1569-1583.

15. Desai SB, Moonim MT, Gill AK, Punia RS, Naresh KN, Chinoy RF: Hormone receptor status of breast cancer in India: a study of 798 tumors. Breast 2000, 9:267-270.

16. Valentini $M$, Mari $E$, Belfiglio $M$, Nicolucci A: Is adjuvant Tamoxifene used optimally in the treatment of breast cancer? Results of an Italian survey. Ann Oncol 1999, 10:789-793.

17. Nandakumar A, Anantha N, Venugopal TC, Sankaranarayanan R, Thimmasetty K, Dhar M: Survival in breast cancer: a populationbased study in Bangalore, India. Int / Cancer 1995, 60:593-596.

18. Gajalakshmi CK, Shanta V, Swaminathan R, Sankaranarayanan R, Black $\mathrm{RJ}$ : A population-based survival study on female breast cancer in Madras, India. Br J Cancer 1997, 75:77I-775.

19. Nair MK, Sankaranarayanan R, Nair KS, Amma NS, Varghese C, Padmakumari $G$, Cherian T: Overall survival from breast cancer in Kerala, India, in relation to menstrual, reproductive, and clinical factors. Cancer 1993, 71:179/-1796.

Publish with Bio Med Central and every scientist can read your work free of charge

"BioMed Central will be the most significant development for disseminating the results of biomedical research in our lifetime. "

Sir Paul Nurse, Cancer Research UK

Your research papers will be:

- available free of charge to the entire biomedical community

- peer reviewed and published immediately upon acceptance

- cited in PubMed and archived on PubMed Central

- yours - you keep the copyright

Submit your manuscript here:

http://www.biomedcentral.com/info/publishing_adv.asp
BiolMedcentral 